\title{
The Discussion of Economic Growth Models and their Future Development
}

\author{
Jinjun $\operatorname{Lin}^{1, a}$ \\ ${ }^{1}$ School of Mathematics and Statistics, Wuhan University, WuHan 430072, China \\ a2015301000005@whu.edu.cn
}

Keywords: Economic growth theory, Endogenous, Solow model.

\begin{abstract}
In 1939, the British economist Harold established the first economic growth model in the history of modern economics [1]. This marks the introduction of mathematics into the economic theory, which means present-day analysis of economic development has provided more accurate theoretical explanation than the previous theories. Later economists not only conducted researches on the basis of Harold economic growth model, but also put forward a number of different models of economic growth. This article will use two parts to introduce and to discuss comparatively classic examples of these models. These examples play a pivotal role in the development of economic growth models. Finally, according to the discussion of these models, this paper presents three possible future models of economic growth.
\end{abstract}

\section{Introduction}

Economic development runs through the entire history of human society. People have long been exploring the inherent laws of economic development. For example, Ancient Greece- Xenophon, Heraclitus, Pythagoras and others had published views on economic activity [2]. However, these opinions were very rough and unstructured. They did not make economics an independent discipline. It is acknowledged that the formal birth of economics is the publication of "Wealth of Nations" written by Adam Smith. His thoughts of "invisible hand" and "liberalism" mentioned in the article have a profound impact on future generations. However, this was not enough. Purely written and logical inferences could only describe the general outline of economic development. Economists faced difficulties when more rigorous and quantitative results were needed. With the further development of economics, economists had introduced the mathematics marginal analysis method into the economy. Since then, economic growth model theory boarded the stage of history, which can be seen as the revolution. It introduced mathematics into economics, and mathematics has quickly become an important part of mainstream economists' theories. In the history of economic growth theory in the past century, many excellent models of economic growth have emerged. They have well portrayed the law of economic growth, through which, people can make more accurate forecasts of the future economic development and can get closer to the essence of economic development. Below, I will look at some of the more classic models, and give a detailed introduction and discussion.

\section{Neoclassical Growth Model and Its Evolutionary Model}

\section{Solow Model}

Solow published "on economic growth theory of a paper" in 1956, which marked the birth of the Solow model [1]. In the Solow model, there are four basic variables: the validity of output Y, capital K, labor L, knowledge or technological progress A, and five basic assumptions: 1. There is only one output of society, which can be used for consumption, or be used for investment. 2 . The depreciation rate of capital is $\delta>0.3$. The production function is Harold neutral, and satisfies constant returns to scale, the law of diminishing marginal utility and Inada Conditions. 4. Population growth, technological progress, and savings rates are exogenous variables. 5. The labor force is always fully employed [4]. According to the mathematical derivation, Solow had got the differential equation that characterizes economic growth: $k=s f(k)-(n+g+\delta) k$. [5] In this 
equation, the existence of a balanced growth path is a natural thing, not a "balance on the blade." This enabled it to solve the core problem in the Harold model. Not only that, it also revealed the dynamic balance of economic growth process, that is, product and production factors of supply and demand balance. This is almost the basic prerequisite for all the economic growth theory behind.

However, the Solo model is not perfect. It exists a lot of problems. For example: There are too much exogenous variables in his model. As a result, the latter economists had proposed a variety of endogenous growth models to revise the Solow model. The R-C-K model is one of the most wellknown ones.

\section{R-C-K Model}

The R-C-K model made the savings rate from the Solow model endogenous. The savings rate is determined by the maximum utility of the family under certain constraints. And the R-C-K model divided the discussion of the model into two parts, family and firm. The family provides consumption, capital, and labor (affected by the technical factor A ( $t$ )). The firm determines the production function. Technological progress $\mathrm{A}$ is exogenous and the growth rate is $\mathrm{g}$. The size of the family grows at rate $\mathrm{n}$, regardless of death. We can derive the expression of consumption change and characterization of capital change by mathematical derivation $[6,7,8] \cdot \frac{\mathrm{c}(\mathrm{t})}{\mathrm{c}(\mathrm{t})}=\frac{\mathrm{r}(\mathrm{t})-\rho-\theta \mathrm{g}}{\theta} ; \mathrm{k} \dot{(\mathrm{t})}$ $=\mathrm{f}(\mathrm{k}(\mathrm{t}))-\mathrm{c}(\mathrm{t})-(\mathrm{n}+\mathrm{g}) \mathrm{k}(\mathrm{t}) \cdot$.[4] In this differential equation, $\mathrm{c}(\mathrm{t})$ represents consumption ; $\rho$ represents the discount rate; The $\mathrm{r}(\mathrm{t})$ is the true rate of return of capital and since the model does not take into account the depreciation of capital, $\mathrm{r}(\mathrm{t})=(\mathrm{f}(\mathrm{k}(\mathrm{t}))) ; \theta$ represents the intertemporal alternative elasticity, which affects the current and future consumer willingness. From the comparison between the Solow model and R-C-K model, it can be seen that the R-C-K model is consistent with the Solow model when describing capital, so the Solow model is the special case of the R-C-K model considering the depreciation of capital and the constant savings rate. Although the two methods are slightly different in the analysis method, there is no essential difference between the nature of the model and the basic conclusion

\section{Modern Economic Growth Model}

In recent decades, modern economists have made many expansions and extensions to the above two models. Endogenous Model of Human Capital is a relatively successful attempt. The human capital model originated in the late 1950s and early 1960s. Due to the efforts of Becker, Schultz, Lucas, Barro and others famous economists, the model became a matured theory. Here mainly discusses Lucas and Barro's human capital model.

\section{Lucas Model}

The most important feature of the Lucas model is to construct a special production function for the generation and accumulation of human capital, that is, $\mathrm{Y}=\mathrm{AK} \wedge{ }^{\wedge}[\mathrm{uNh}]^{\wedge}(1-\beta)\left[\mathrm{h} \_\alpha\right]^{\wedge} \gamma,[9]$ where $\beta$ is the income share of the offspring; $\mathrm{h}_{\alpha}{ }^{\gamma}$ reflects the external effects of human capital, $\mathrm{u}$ is the time for workers to participate in the production of material capital (then, $1-u$ is the time to invest in human capital). It is clear that the production function belongs to the Cobb-Douglas function. For ordinary material capital K, Lucas thought it satisfied $\mathrm{K}=\mathrm{Y}-\mathrm{Nc}$. [7] and for the accumulation of human capital, Lucas argued that it was different from the accumulation of material capital, it should meet $h^{\circ}=h \delta(1-u)$. [7] It can be seen from this equation that if there is no investment in the accumulation of human capital (when $\mathrm{u}=1$ ), there is no accumulation of human capital $(\mathrm{h}=0)$; if all the time is consumed for the accumulation of human capital (when $\mathrm{u}=0)$, the growth rate of human capital reaches the maximum value $\delta\left(\frac{\dot{h}}{h}=\delta\right)$. Through further mathematical derivation [9], Lucas had obtained a balanced growth rate and optimal growth rate of human capital on a balanced growth path. Lucas found that both two human capital growth rates increased with the increase in the efficiency of human capital investment $\delta$, and decreased with the increase of the discount rate. At the same time, in the Lucas model, even if labor is zero growth, the economy will continue to grow. This is the fundamental difference between Lucas and Solow models or R-C-K model. 
However, in the Lucas model, the way to characterize material capital and human capital accumulation is very rough, which limits the Lucas model to further conclusions. Thus, Barro in 1996, proposed a more accurate model on the basis of predecessors.

\section{Barro Model}

Barro, at first, used the Cobb-Douglas function to measure the influence of each factor of production, namely: $Y=A K^{\alpha} S^{\beta} H^{\gamma}\left(\operatorname{Le}^{\mathrm{xt}}\right)^{1-\alpha-\beta-\gamma}[10]$, where $\alpha, \beta, \gamma>0$, and $0<\alpha+\beta+\gamma<1$. Then, he divided the equation on both sides by $\mathrm{Le}^{\mathrm{xt}}$, thus getting the per capita production function per unit time: $\hat{y}=A \hat{k}^{\alpha} \hat{s}^{\beta} \hat{h}^{\gamma}$ [8]. We have known that the total investment $i$, in the model, was divided into three parts, namely: physical capital investment $\hat{i}_{k}$, education investment $\hat{i}_{s}$, health investment $\hat{\mathrm{i}}_{\mathrm{h}}$. According to the derivation of the differential equation in the Solow model, it can be easily derived that the differential equations for $\mathrm{k}, \mathrm{s}, \mathrm{h}$, are: $\hat{k}=\hat{i}_{k}-(n+x+\delta) \hat{k} ; \hat{s}=\hat{i}_{s}$ $-(n+x+d) \hat{s} ; \hat{h}=\hat{i}_{h}-(n+x+d) \hat{h}[8]$, where $\delta$ is the depreciation rate of material capital, and $\mathrm{d}$ is the depreciation rate for educational capital and healthy capital.

Barro focused on the discussion of $d$. Barro thought that $d$ could be written as a function of $h$, i.e. $\mathrm{d}=\mathrm{d}(\mathrm{h})$. This function is monotonically decreasing, and has positive lower bound, which is because the depreciation of healthy capital comes mainly from human death or disease. If a person is healthier, then the probability of his death and the probability of getting sick is smaller. As a result, the depreciation rate of his healthy capital will be smaller. However, we have already known that no matter how healthy a person is, the minimum probability of his illness or death cannot be 0 , so this function has a positive lower bound $d_{0}$.

Through the previous analysis and mathematical derivation, Barro has obtained the differential equation for the growth rate of consumption: $\frac{c(t)}{c(t)}=\frac{\alpha \mathrm{A} \hat{k}^{\alpha-1} \hat{S}^{\beta} \hat{h}^{\gamma}-\delta-\rho}{\theta}$ [8] the differential equation is divided into three forms according to the selected capital types: $\alpha \mathrm{A} \hat{k}^{\alpha-1} \hat{s}_{S}^{\beta} \hat{h}^{\gamma}-\delta=\beta \mathrm{A} \hat{k}^{\alpha{ }^{\alpha} \beta-1} \hat{h}^{\gamma}-d$ $=\gamma \mathrm{A} \hat{k}^{\alpha \wedge} \hat{s}^{\gamma-1}-(s+h)\left(\frac{\partial d}{\partial h}\right)-d \circ[10]$

This equation reveals that the impact of material capital on consumption has some consistency with the impact of educational capital on consumption (their mathematical forms are essentially the same, and the depreciation of material capital and the depreciation of educational capital are the same in the expression). There is also a very important point for: the rise in health capital makes $\mathrm{d}$ decline, thereby enhancing the return of educational capital. And increase of the return on education capital renders the investment in education capital higher. This is very much in line with our life experience. When a person is young (i.e., the depreciation rate of healthy capital is low), we are more willing to spend time learning. And when we are old (that is, the high depreciation rate of health capital), most of us do not have the desire of learning.

For $(s+h)\left(\frac{\partial d}{\partial h}\right)$, it affects the ratio change of $\mathrm{k}, \mathrm{s}, \mathrm{h}$ in $\mathrm{y}$. According to Barro's discussion [10], with economic growth, the proportion of investment in education and health investment will grow, and the proportion of investment in physical capital will become smaller.

The relative size of educational capital and healthy capital depends on the size of $(s+h)\left(\frac{\partial d}{\partial h}\right)$. If $(s+h)$ becomes larger, then the proportion of investment in health capital will be greater than the proportion of investment in education capital. If $\left(\frac{\partial d}{\partial h}\right)$ becomes smaller, the result is the opposite. This suggests that when the country is poorer, people will give priority to meeting the needs of health (this is because the increase in $(\mathrm{s}+\mathrm{h})$ is the main factor). And when the country becomes richer, $\left((s+h)\right.$ grows less, and people are getting healthier, so $\left(\frac{\partial d}{\partial h}\right)$ becomes smaller, $)$, people will be more concerned about the investment in education. 


\section{The Development Trend of Economic Growth Theory}

There are many other economic models besides the more classic models above. For example, the theory of intergenerational transmission that links human capital theory with intergenerational income flows; the environmental capital model that introduces environmental capital as an important influencing factor; the industrial structure theory from the production structure that examines the transfer of labor and capital in different production sectors and the structural effect of this shift on economic growth. And these models (including the above highlighted), show the following trends:

\section{More Endogenous Variables}

From the Solow model to all kinds of model theories at persent, in a sense, more exogenous variables in the predecessor model are endogenized. Therefore, we have reasons to believe that in the future research, endogenous is still the focus of economic growth theory. So what is the direction of the development of the endogenous model? The author thinks that the introduction of sociology, psychology into the content of economic growth model may be able to get the results that the predecessors have not been. All economic activities, in the final analysis, are human activities. Then the importance of natural attributes and social attributes of human beings in the economic growth is self-evident. Sociology, and psychology are also the subjects of human behavior, then people can use some of the conclusions of these two disciplines to construct some new endogenous variables into the model. In fact, the intertemporal alternative elasticity $\theta$ in the R$\mathrm{C}-\mathrm{K}$ model mentioned above is related to consumer psychology. But this character is very rough, perhaps people can use some of the conclusions of psychology, put forward other consumer psychology of the endogenous model.

\section{Consider the Influence Between the Two Economies and Above}

The models highlighted above only consider the interaction of the various factors of production within a single economy. However, for the rapid development of global economic and trade today, only the study of the internal development of a single economy, simply cannot show the whole picture of economic development, and even come to the wrong conclusion. The impact of external economies, for their own economic development has been, cannot be ignored. Therefore, the author thinks that the study of the interaction between multiple economies will become a hot area of economic growth model research. However, since the factors affecting multiple different economies are more complex, all the influencing factors cannot be considered, so how to filter the main influencing factors should be the most crucial and pivotal step of the establishment of a new model.

\section{Introduce New Math Tools}

We must admit that the differential equation in the portrayal of economic activity in this area, has a unique advantage. It can more perfectly show the dynamic balance of economic development. However, in our economic activities, not all processes are "continuous" over time. For example, when we consider the consumer's decision, it has only two options: buy or not to buy. We can only use discrete mathematical form to express this variable. In the 1970s and 1980s, the development of discrete selection model reflected the introduction of discrete mathematics. This is just an example. With the new mathematical theory, the author believes that we can always choose the mathematical tools they need to describe economic behavior. In the future development of economic growth theory, the application of mathematics will certainly be one of the main themes.

\section{References}

[1] JIN Yuan.A Review of the Development and Application of Solow's Economic Growth Model [J]. Modem Business, 2012, (17): 28-29 
[2] Pengzheng Sui, Huang Zhuoyan, Li Gefei, etc. The necessity of establishing economic philosophy from the historical origin [J] .Zhongnan University of Economics and Law, 1987 (2): 66-71.

[3] Nie Wenjun Adam Smith economic ethics research [D]. Hunan Normal University, 2003.

[4] Liu Guodong. The development of modern economic growth theory [D]. Shanghai: Shanghai Jiaotong University, 2009: 1-43

[5] Robert M. Solow. A Contribution to the Theory of Economic Growth [J].The Quarterly Journal of Economics, Vol.70, No.1 (Feb.1956):65-94

[6] F. P. Ramsey. A Mathematical Theory of Saving [J].The Economic Journal, Vol. 38, and No.152 (Dec., 1928):543-559

[7] David Cass. Optimum Growth in an Aggregative Model of Capital Accumulation [J] the Review of Economic Studies, Vol. 32, No. 3 (Jul., 1965):233-240

[8] Koopmans T C. On the Concept of Optimal Economic Growth [J]. Cowles Foundation Discussion Papers, 1963, 28.

[9] Robert E. Lucas. On the mechanics of economic development [J]. Journal of Monetary Economics, 1988, Vol.22 (1):3-42

[10] Robert J.Barro. Health and Economic Growth [J]. Annals of Economic and Finance, 2013, 142:329-366. 